\title{
The case for prostate capsule-sparing radical cystectomy in selected patients
}

\author{
Laurence Klotz, MD, MSc, FRCSC;* Jehonathan Pinthus, MD, PhD ${ }^{\dagger}$
}

Can Urol Assoc J 2009;3(Supp|4):S215-9

$\mathrm{R}$ adical cystoprostatectomy and neobladder replacement have become the gold standard for patients with invasive bladder cancer. Although the neobladder represents a significant improvement over ileal conduit, in terms of the effect on body image, the operation has a significant impact on many quality-of-life-related domains. Erectile function and incontinence (particularly nocturnal) are common. Nerve-sparing cystectomy is associated with a relatively low rate of erectile function preservation. ${ }^{1}$

The impetus for traditional cystectomy including en bloc dissection of the entire prostate arose because of reports that occult transitional cell carcinoma (TCC) and prostate cancer were prevalent in the prostate of these men. In this article, we present the case that prostate capsule-sparing radical cystectomy, with appropriate and careful patient selection and surgical technique reduces the risk of local recurrence and improves quality of life.

\section{Prostate-sparing techniques}

Different techniques have been described, with several common motifs. All of these techniques preserve a portion of the prostatic capsule, the seminal vesicles and the vas deferens, but vary in the types of prostate resection and neobladder configuration. ${ }^{2}$ Importantly, all authors advocate removal of part of the prostate. "Prostate sparing" actually refers either to subtotal prostatic resection or resection of the adenoma with capsule sparing.

The two main techniques are (1) removal of the prostatic adenoma using the technique of a Millen simple retropubic prostatectomy, excising the adenoma tissue containing the prostatic ducts and most acini, leaving the surgical capsule and seminal vesicles intact, ${ }^{3}$ and (2) a transverse excision through the proximal prostate, leaving the distal prostate, including the distal adenoma and seminal vesicles and utricle, intact. ${ }^{4}$ In both cases, the neurovascular bundle, the distal sphinteric complex, and the continuity of the vas, seminal vesicles and ejaculatory duct remain undisturbed.

The critical two questions are (1) What is the risk of local recurrence in the residual prostate tissue? and (2) What are the quality-of-life results (e.g., voiding, continence and erectile function)?

Patient selection is a critical component of the procedure. Patients who are at increased risk for prostatic urethral involvement should be excluded. Identifying these patients involves several steps. Patients should be candidates for a neobladder on the basis of age, comorbidity, and extent of disease. T4 cases are excluded. The primary cancer should not directly involve the bladder neck or prostatic urethra. Diffuse, multifocal carcinoma in situ (CIS) increases the risk of prostatic involvement and is a contraindication. (Focal CIS in the peri-tumoural area is not a contraindication.) Patients who have no CIS, multifocality or bladder neck involvement have an extremely low rate of prostatic urethral involvement; in one series, 0 of 40 patients experienced prostatic urethral involvement. ${ }^{5}$

Transurethral biopsies of the prostatic urethra should be performed, ideally at the time of the initial transurethral resection, to identify occult ductal or acinar involvement of the prostate. Multiple transurethral biopsies should be taken, particularly at the distal prostate proximal to the ejaculatory duct, where the highest concentration of ducts is present. These biopsies must show no evidence of prostatic involvement.

Patients should be screened for prostate cancer, with a normal digital rectal exam (DRE), normal transrectal ultrasound and a prostate-specific antigen (PSA) consistent with a relatively low risk of prostate cancer. In patients in whom prostate cancer is suspected, a 10-12 core transrectal ultrasound-guided biopsy of the prostate is warranted.

Some authors have advocated a full transurethral resection of the prostate and/or extensive transrectal prostate biopsies prior to the procedure (regardless of PSA and DRE findings). ${ }^{6.7}$ These are unnecessary in most patients. They subject the patient to an additional procedure, and likely have a low incremental utility beyond extensive transurethral biopsies.

\section{The proposed procedure}

To reduce the risk of tumour spillage, maximal tumour cytoreduction by transurethral resection of bladder tumour should be performed prior to surgery. The cystectomy is performed antegrade in standard fashion. After the peritoneum is 
transversely incised at the level of the cul-de-sac, a plane is created between posterior bladder wall and both seminal vesicles and vasae. Sharp dissection of the bladder from seminal vesicles, ejaculatory ducts and deferential ampullae is performed. Closure of the bladder neck before final dissection of the bladder from the prostate is performed to reduce tumour spillage. The anterior prostatic capsule is transversally incised. The plane between the adenoma and the surgical capsule is then dissected with sharp and blunt dissection, as described by Millen's technique for simple retropubic prostatectomy. ${ }^{3}$ The goal is a complete adenectomy. The adenoma should remain attached at the bladder neck; this is generally not difficult to achieve. The procedure is easier in men with prostatic enlargement.

In men without prostatic enlargement, the plane between the surgical capsule and adenoma may not be readily dissectible. In these cases, the transverse incision should be extended throughout the entire prostate about $1 \mathrm{~cm}$ superior to the apex, leaving the apical tissue, including the veru and seminal vesicles. Where possible, prostatic capsule should be spared anteriorly.

The residual posterior pedicles are then divided and the bladder and prostatic adenoma removed. The bladder neck and prostatic adenoma are examined by frozen section to exclude malignancy. A positive prostatic margin warrants complete resection of the residual prostate.

After an extended lymphadenectomy, taking care to preserve the nervi erigenti in the peri-rectal region, an ileal neobladder is created and anastomosed to the prostatic capsule with interrupted stitches. The capsular sutures should be placed close to the prostatic apex.

\section{Oncologic concerns}

\section{Prostatic involvement by TCC}

In unscreened patients, the incidence of prostatic involvement by TCC in cystectomy specimens is $20 \%$ to $48 \%$ (Table
1)..$^{5,8-12}$ These figures include CIS and severe dysplasia, as well as ductal or stromal involvement. Prostatic apical involvement occurs in $15 \%$ to $33 \% .{ }^{9,10}$

The critical questions are a) whether prostatic involvement can be identified prior to or during surgery, and b) when, in spite of attempts to identify prostatic involvement preoperatively, ductal or acinar involvement is present, a capsule-sparing approach where the adenoma and glandular elements are largely resected, provides an adequate oncologic outcome.

The evidence suggests yes. Prostatic involvement tends to occur in a stepwise fashion, from urethral, to ductal, to stromal involvement. Excluding patients with cancer at the bladder neck will select a group at lower risk of prostatic involvement. Extensive sampling of the prostatic urethral is likely to identify urethral and ductal involvement.

Further, gross involvement of the prostate is often palpable. A recent study of 128 radical cystoprostatectomy specimens (1988 to 2003 ) in whom $39 \%$ had prostatic involvement found that $78 \%$ were detected by prostatic urethral biopsy. Of the remainder, $14 \%$ had direct extension into the prostate and $14 \%$ had extracapsular or seminal vesicle involvement, usually suspected on DRE. ${ }^{11}$ Finally, frozen section of the prostatic margin will identify additional patients whose prostatic urethral involvement had still not been identified. Eleven recent series of prostatesparing cystectomy where patients were screened for prostatic involvement for TCC report an incidence of local recurrence of about $3 \%$. This is considerably lower than the rate for cystoprostatectomy series, and clearly indicates that prostatic involvement can be identified preoperatively (Table 2). ${ }^{7,13-22}$

\section{Occult prostate cancer}

Coexistent prostate cancer exists in patients with invasive bladder cancer at approximately the same frequency as in normal men. The risk of prostate cancer incidence or mortality is not any higher in bladder cancer patients than in

Table 1. Incidence of prostate urethral transitional cell carcinoma and prostate cancer in prostates removed during cystoprostatectomy

\begin{tabular}{|c|c|c|c|c|c|c|}
\hline Author & $\mathrm{n}$ & $\begin{array}{l}\text { TCC prostatic } \\
\text { involvement }\end{array}$ & $\begin{array}{c}\text { Urethra/ducts, } \\
\%\end{array}$ & $\begin{array}{l}\text { Stroma, } \\
\%\end{array}$ & $\begin{array}{l}\text { Prostate } \\
\text { cancer, \% }\end{array}$ & $\begin{array}{l}\text { Molecular significant for } \\
\text { prostate cancer, \% }\end{array}$ \\
\hline Montie, $1989^{\circ}$ & 72 & N/A & N/A & N/A & 46 & 7 \\
\hline Revelo, $2004^{9}$ & 121 & 48 & 37 & 11 & 41 & 20 \\
\hline Kefer, $2005^{5}$ & 171 & 32 & 19 & 15 & 36 & 25 \\
\hline Pettus, $2006^{10}$ & 122 & 32 & 9 & 23 & 47 & 12 \\
\hline Shen, $2005^{11}$ & 214 & 32 & 14 & 5 & N/A & $\mathrm{N} / \mathrm{A}$ \\
\hline Weizer, 2006 ${ }^{12}$ & 35 & 23 & 14 & 9 & 47 & 12 \\
\hline
\end{tabular}


The case for prostate capsule-sparing radical cystectomy

Table 2. Incidence of local and distant recurrence of transitional cell carcinoma and concurrent prostate cancer in prostate-sparing cystectomy series

\begin{tabular}{|c|c|c|c|c|c|}
\hline Author & $\mathrm{n}$ & Stage $\leq \mathrm{pT} 2, \%$ & Local, \% & Distant, \% & Prostate cancer, \% \\
\hline Vallencien, $200^{27}$ & 100 & 64 & 3 & 14 & 5 \\
\hline Botto, $2004^{13}$ & 34 & 65 & 3 & 12 & 3 \\
\hline Muto, $2004^{14}$ & 61 & 98 & 0 & 19 & 2 \\
\hline Colombo, $200^{46}$ & 27 & 96 & 0 & 0 & 0 \\
\hline Terrone, $2004^{16}$ & 27 & 93 & 0 & 15 & 0 \\
\hline Abuzied, $2005^{17}$ & 45 & 100 & 7 & 9 & N/A \\
\hline Min, $2005^{18}$ & 12 & 100 & 0 & 17 & N/A \\
\hline Martis, $2005^{19}$ & 32 & 47 & 0 & 0 & 0 \\
\hline Wunderlich, $2006^{20}$ & 31 & 84 & 3 & 0 & 0 \\
\hline Thorstensen, $2008^{21}$ & 25 & N/A & 0 & 20 & 16 \\
\hline Simone, $2008^{22}$ & 20 & 100 & 20 & 30 & $\mathrm{~N} / \mathrm{A}$ \\
\hline Total & 414 & & & & \\
\hline
\end{tabular}

the normal population. In the context of the aggressive lethality of invasive bladder cancer, the mortality risk of coexistent prostate cancer, which is likely to be slow growing even if clinically significant, is small. In addition, with appropriate screening (including PSA, transrectal ultrasound, and 10-14 core biopsy where indicated), most patients with clinically significant disease are likely to be identified. In the unusual case where clinical prostate cancer arises in a patient who has had a capsule-sparing cystectomy and neobladder, salvage options exist.

Coexistent prostate cancer in cystoprostatectomy specimens is found in $23 \%$ to $47 \%$ of men undergoing cystectomy (Table 1). In contrast, synchronous or metachronous prostate cancer in prostate-sparing series, where patients were screened for pre-existing prostate cancer, occurs in $2 \%$ to $4 \%$ (Table 2). ${ }^{7,13-22}$ Occasionally, even with this thorough screening, prostate cancer may develop. Vallancien and colleagues found that 3 of 100 men developed prostate cancer postoperatively. ${ }^{7}$ In 11 reported series of prostatesparing cystectomy, 12 of 369 patients (3\%) were found to have prostate cancer. Further, prostate cancers diagnosed after a negative initial screen are likely to be smaller volume and more indolent. Thus, appropriate screening appears to identify almost all men with significant prostate cancer. With this approach, the possible presence of small volume occult prostate cancer is a non-issue.

\section{Recurrence rates}

In radical cystectomy series, recurrence occurs in about $30 \%$ at 5 years and $40 \%$ at 10 years. ${ }^{23}$ Local control is achieved effectively by cystoprostatectomy, ranging from $5 \%$ to $19 \%$. Local and systemic recurrence rates after prostate sparing cystectomy is reported in $0 \%$ to $3 \%$ of patients in the 11 series in the literature. Summarizing the world experience, local recurrence has occurred in 12 of the 369 patients $(3.3 \%)$ and systemic recurrence in 48 of the 369 patients $(13 \%)$. Bearing in mind the critical role of patient selection in determining recurrence rates, this rate is clearly comparable to other cystectomy series.

There is controversy regarding the interpretation of this literature. A limitation of the existing data is that the median follow up has been $\leq 3$ years in 9 of the 11 series in the literature. Two series have long follow-up: 27 patients with a mean follow-up of 90 months, ${ }^{16}$ and 61 patients with mean follow-up of 68 months. ${ }^{14}$ The recurrence rate in these 2 series is no higher.

However, 1 review of 7 series involving 306 patients with $\mathrm{T} 2$ or less disease calculated a similar systemic recurrence rate of $13 \%$, but concluded that this was 2 times higher than the rate expected from classical cystoprostatectomy. ${ }^{24}$ This conclusion, insofar as it assumed an extremely low rate of recurrence with the standard operation for purposes of comparison, was polemical.

These low rates are reassuring, even if they reflect patient selection. If one minimizes the risk that the prostate capsule left behind contains TCC and strictly avoids intraoperative spillage, the odds that the retained prostate tissue would be the source of recurrence are low. 
Klotz and Pinthus

Table 3. Functional outcome of prostate-sparing cystectomy

\begin{tabular}{|c|c|c|c|c|}
\hline Author & $\mathrm{n}$ & Day continence, $\%$ & Night continence, \% & Potency, \% \\
\hline Vallencien, $2002^{7}$ & 100 & 97 & 95 & 82 \\
\hline Botto, $2004^{13}$ & 42 & 80 & 80 & 90 \\
\hline Muto, $2004^{14}$ & 61 & 95 & 31 & 95 \\
\hline Colombo, 2004 & 27 & 100 & 100 & 100 \\
\hline Terrone, $2004^{16}$ & 27 & 100 & 77 & 93 \\
\hline Abuzied, $2005^{17}$ & 20 & 100 & 100 & 90 \\
\hline Arroyo, $2005^{29}$ & 25 & 100 & 100 & 84 \\
\hline Martis, $2005^{19}$ & 32 & 98 & 83 & 80 \\
\hline Wunderlich, $2006^{20}$ & 31 & 94 & 94 & 87 \\
\hline Thorstensen, $2008^{21}$ & 25 & 85 & 50 & 95 \\
\hline Simone, $2008^{22}$ & 20 & 100 & 100 & 100 \\
\hline
\end{tabular}

\section{Functional results following prostate-sparing cystectomy}

Preservation of erectile function is reported in $13 \%$ to $50 \%$ of patients undergoing nerve-sparing cystectomy. ${ }^{25-28}$ In contrast, all 11 published series of prostate-sparing cystectomy report $80 \%$ or greater rates of potency preservation, and 6 describe $90 \%$ or greater preservation (Table 3 ). Because the capsule-sparing approach leaves the entire prostatic neurovascular region intact, this rate is perhaps unsurprising.

Continence is also improved. The rate of day and nighttime continence following standard cystoprostatectomy and ileal neobladder at centres of excellence is $90 \%$ and $80 \%$, respectively. In contrast, the prostate-sparing series report a higher level of continence. Nine series report daytime continence rates of $94 \%$ or greater. Nighttime continence was achieved in $94 \%$ or more in 7 series, and only 1 author $^{14}$ reported a rate of nighttime incontinence $>50 \%$. Six series report daytime and nighttime incontinence rates of $100 \%$ !

These studies assessed continence, as reported by physicians in most cases, and did not use validated questionnaires or other more objective means of assessment. However, the results are encouraging.

In these cases, a trade-off between the functional benefits of prostate sparing and the oncologic benefits of cystoprostatectomy must be balanced.

\section{Conclusion}

Prostate capsule-sparing cystectomy is an appealing modification of conventional cystoprostatectomy. Preservation of the capsule, which includes the neurovascular bundle and components of the distal sphincter mechanism, appears to result in an improved functional outcome, with superior rates of preservation of erectile function and continence. Improved quality of life makes cystectomy a more accept- able treatment option to patients, thereby avoiding the risks inherent in conservative management of borderline cases.

Patient selection is critical. Prostatic involvement by TCC or prostate cancer must be ruled out by appropriate diagnostic maneuvers prior to the operation. The experience to date suggests that by selecting patients with a low risk of prostatic involvement, avoiding intraoperative spillage, and obtaining frozen sections of the prostate margin, the odds that the retained prostate capsule will be the source of recurrence or clinically significant prostate cancer are low, while quality of life is improved.

From the *Department of Surgery, Division of Urology, Sunnybrook Health Sciences Centre, University of Toronto, Toronto, ON; 'Division of Urology, McMaster University, Hamilton, ON

Competing interests: None declared.

This paper has been peer-reviewed.

\section{References}

1. Schoenberg M P, Walsh PC, Breazeale DR, et al. Local recurrence and survival following nerve sparing radical cystoprostatectomy for bladder cancer: 10-year followup. J Urol 1996;155:490-4.

2. Tal R, Baniel J. Sexual function-preserving cystectomy. Urology 2005;66: 235-41.

3. Millin T. Retropubic prostatectomy: a new extravesical technique. Report on 20 cases. Lancet 1945; 2:693-6.

4. Spitz A, Stein JP, Lieskovsky G, et al. Orthotopic urinary diversion with preservation of erectile and ejaculatory function in men requiring radical cystectomy for nonurothelial malignancy: A new technique. J Urol 1999;161:1761-4.

5. Kefer JC, Voelzke BB, Flanigan RC, et al. Risk Assessment for occult malignancy in the prostate before radical cystectomy. Urology 2005;66:1251-5.

6. Colombo R, Bertini R, Salonia A, et al. Overall clinical outcomes after nerve and seminal sparing radical cystectomy for the treatment of organ confined bladder cancer. J Urol 2004;171:1819-22.

7. Vallancien G, Abou El Fettouh H, Cathelineau X, et al. Cystectomy with prostate sparing for bladder cancer in 100 patients: 10-year experience. J Urol 2002;168:2413-7.

8. Montie JE, Wood DP Jr, Pontes JE, et al. Adenocarcinoma of the prostate in cystoprostatectomy specimens removed for bladder cancer. Cancer 1989;63: 381-5. 
9. Revelo MP, Cookson MS, Chang SS, et al. Incidence and location of prostate and urothelial carcinoma in prostates from cystoprostatectomies: implications for possible apical sparing surgery. J Urol 2004;171: 646-51.

10. Pettus JA, Al-Ahmadie H, Barocas DA, et al. Prostate involvement by urothelial and prostatic carcinomas in radical cystoprostatectomy specimens. Paper presented at: The 2006 Annual Meeting of the American Urological Association, May 20-25, 2006; Atlanta, GA.

11. Shen Steven SS, Amiel Gilad E, Truong Luan D, et al. The sensitivity of transurethral biopsy for detecting prostatic involvement by transitional cell carcinoma in patients undergoing radical cystoprostatectomy. Paper presented at: The 2005 Annual Meeting of the American Urological Association, May 21-May 26, 2005, San Antonio, TX.

12. Weizer AZ, Shah RB, Gilbert SB, et al. Presence, location and significance of prostate cancer in patients undergoing radical cystoprostatectomy: Feasibility of prostate-capsule sparing cystectomy. Paper presented at: The 2006 Annual Meeting of the American Urological Association, May 20-25, 2006; Atlanta, $G$.

13. Botto H, Sebe P, Molinie V, et al. Prostatic capsule and seminal-sparing cystectomy for bladder carcinoma: Initial results for selected patients. BJU Int 2004;94:1021-25.

14. Muto G, Bardari F, D'Urso L, et al. Seminal sparing cystectomy and ileocapsuloplasty: Long-term followup results. J Urol 2004;172:76-80.

15. Colombo R, Bertini R, Salonia A, et al. Overall clinical outcomes after nerve and seminal sparing radical cystectomy for the treatment of organ confined bladder cancer. J Urol 2004;171:1819-22.

16. Terrone C, Cracco C, Scarpa RM, et al. Supra-ampullar cystectomy with preservation of sexual function and ileal orthotopic reservoir for bladder tumor: Twenty years of experience. Eur Urol 2004;46:264-70.

17. Abuzeid AM, Saleem MD, Badawy AA, et al. Genital sparing radical cystectomy for organ confined bladder carcinoma. Impact on tumor control and quality of life. J Urol 2005;173A:05-AB-4215-AUA.

18. Min Y, Wei-ming W, Ying-iian Z. Clinical outcomes of nerve and seminal sparing cystectomy for the treatment of malignant and non-malignant bladder disease. Paper presented at: The 2005 Annual Meeting of the American Urological Association, May 21-May 26, 2005, San Antonio, TX.
19. Martis GD, Elia $G$, Diana $M$, et al. Prostatic capsule- and nerve-sparing cystectomy in organ confined bladder cancer: Preliminary results. World J Surg 2005;29:1277-81.

20. Wunderlich $H$, Wolf $M$, Reichelt 0 , et al. Radical cystectomy with ultrasound-guided partial prostatectomy for bladder cancer: A complication-preventing concept. Urology 2006;68:554-9.

21. Thorstenson A, $O^{\prime}$ Connor CR, Ahonen R, et al. Clinical outcome following prostatic capsule and SV sparing cystectomy in 25 men. Scan J Urol Nephrol 2008;27:1-6.

22. Simone G, Papalia R, Leonardo C, et al. Prostatic capsule and SV sparing cystectomy: improved functional results, inferior oncologic outcome. Urology 2008;72:162-6.

23. Stein JP, Skinner DG. Radical cystectomy for invasive bladder cancer: Long term results of a standard procedure. World J Urol 2006;24:296-304.

24. Hautmann RE, Stein JP. Neoblader with prostatic capsule and seminal-sparing cystectomy for bladder cancer: A step in the wrong direction. Urol Clin North Am 2005;32:177-85.

25. Hautmann RE, De Petriconi R, Gotffried H-W, et al. The ileal neobladder complications and functional results in 363 patients after 11 years of follow-up. J Urol 1999;161:422-8.

26. Maderbascher $S$, Mohrle K, Burkhard F, et al. Long-term voiding patterns of patients with ileal orthotopic bladder substitutes. J Urol 2002;197:2052-7.

27. Henningsohn L, Wijkstrom H, Pedersen J, et al. Time after surgery, symptoms, and well-being in survivors of urinary bladder cancer. BJU Int 2003;91:325-30.

28. Lebret T, Herve JM, Yonneau L, et al. Study of survival after cystectomy for bladder cancer. Report of 504 cases. Prog Urol 2000;10:551-60.

Correspondence: Dr. Laurence Klotz, 2075 Bayview Ave MG 408, Toronto, ON M4N 3M5; fax: 416-480-6121; laurence.klotz@sunnbrook.co 